\title{
Analysis of Mechanical Properties of Shape Memory Alloy
}

\author{
Gözde Konuk Ege ${ }^{* 1}$, Nihat Akkuş ${ }^{2}$, Mücahit Ege ${ }^{2}$
}

Accepted $3^{\text {rd }}$ September 2016

\begin{abstract}
In this study, a particular mechanism is designed to obtain the mechanical properties of shape memory alloys (SMA). Mechanical behaviour occurring due to the super elastic properties is investigated by applying current to shape memory alloys via designed mechanism. Displacement, velocity, time, force physical effects of SMA springs is obtained for different current values, and active operating range of springs is determined. This acquired data are of importance in determining the area of use of shape-memory alloys.

This paper presents the structure of the designed mechanism, and data of mechanical properties of shape memory alloys which is obtained by using this designed mechanism.
\end{abstract}

Keywords: SMA, Shape Memory Alloy, Super elastic, Actuator.

\section{Introduction}

Shape Memory Alloy is a term given to alloy group which have the ability to return to a predetermined shape or size when it exposed to heat [1].

Nowadays, smart materials take their part quickly in the world industry. Shape memory alloys, which is located in the smart materials, have been investigated in terms of industrial applications in Turkey. They own up to $\% 8$ super elastic mechanical properties and this specification has attracted attention of the industry.

Shape memory alloys conserve their deformation shape at room temperature which transitive at high temperature. Deformed shape memory alloy is heated as a resistance by electric current. With this heat it could be transformed from deformed shape to original shape. Shape memory alloys are used industrials of health, automotive, defence etc. Shape memory alloys with shape memory effect provides superiority in terms of more flexible, lightweight and miniaturization. These superiorities are brought about developing process of power transmission organs [2].

As a result of deformation of the shape memory alloy can return to its previous form with minimum work and also it is presented a new perspective that power output throughout phase conversion and power/weight ratio is more than other power transmission organs [3].

Advantages of actuators which are made of Shape memory alloys among other actuators;

- Quite and smooth operation in the smooth system

\footnotetext{
${ }^{1}$ Mechatronic Programme, Gedik Vocational School, Istanbul Gedik University, 34913, Istanbul/Turkey

*Corresponding Author: Email: gozde.konuk@gedik.edu.tr Note: This paper has been presented at the $3^{\text {rd }}$ International Conference on Advanced Technology \& Sciences (ICAT'16) held in Konya (Turkey), September 01-03, 2016.
}

- $\quad$ Power/weight ratio is in desired level

- Steady state

- $\quad$ Engine with low energy

Shape memory alloys are functional materials because of their martensitic transformation and converse transformation such as shape memory effect and super elasticity. Their basic characteristics are that they have two different shape and crystal structure under and above critical transformation temperature.

These materials which could be deformed at relatively low temperatures could be return prior to their shape at higher temperatures [4].

Shape memory effect or shape memory issue is that at the main phase shape memory alloy which have a specific shape is cooled to the martensitic transformation temperature and changed the shape with outer impact and after this material return its first shape with increasing the temperature to the main phase temperature.

At the (Figure.2A) material's internal shape transform to martensitic phase (Figure.2B) from austenite when it is cooled. At this temperature permanent shape deformation is given to the material (Figure.2C). And this material is transformed into austenite phase when it heated (Figure.2D).

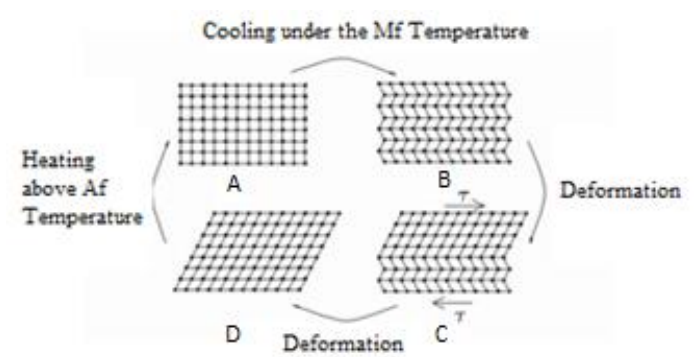

Figure 2. Mechanism of memory function: Austenite phase(A); transformation martensite phase(B); deformation(C); transformation austenite phase(D) [5] 
In this study, an experimental Set-up is developed to observe physical impacts such as depletion, force, velocity related to shape memory alloys' super elasticity mechanical properties throughout shape memory alloys' cooling and heating process [5].

At the (Figure.2A) material's internal shape transform to martensitic phase (Figure.2B) from austenite when it is cooled. At this temperature permanent shape deformation is given to the material (Figure.2C). And this material is transformed into austenite phase when it heated (Figure.2D).

(Donmez B. et al) presents that the shape memory alloy wires can be used in micro-positioning applications successfully. They obtained $0.005 \%$ steady state error which means $0.005 \mathrm{~mm}$ positioning error in $100 \mathrm{~mm}$ of wire. They offer that this error can be reduced by using more accurate position sensors and it can be obtained best results by using Narna-L2 controller.

In this study, an experimental set-up is developed to observe physical impacts such as depletion, force, velocity related to shape memory alloys' super elasticity mechanical properties throughout shape memory alloys' cooling and heating process [5].

\section{Design of Experimental Set-Up}

Obtaining properly material characteristics of titanium and nickel alloys, which is known NiTiNol in industry, have importance since they are widely used to produce biomedical applications and actuators, thus to know their mechanical properties is important to carry out numerical and analytical analysis and simulations. In addition to knowing the relationship between the estimated number of cycles and maximum permissible stress and strain.

In this way, to get mechanical findings two linear actuator is designed as an experimental Set-up. With this Set-up is aimed to be guide for determining the mechanical behaviour of the shape memory springs.

Shape memory alloys' mechanical behaviour have great importance to design valve, actuator, mechanical muscle etc. and to investigate new industrial applications.

For the purpose of the study, two different experimental Set-up is designed.

\subsection{Experimental Set-Up}

Shape memory alloy behaviour to be tested in the set-up are measured by the Module- 1 and Module- 2 which are operated as an actuator. Shape memory springs are heated by electric current. High level current is necessary for deformation of springs because of that insulation is provided in areas where contact springs.

At the (Figure.3), experimental set up is observed which was designed to determine characteristic structures of the shape memory alloys.
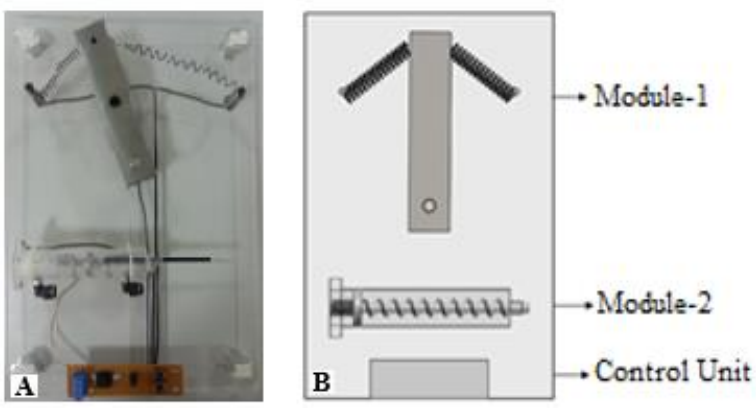

Figure 3. Picture of experimental set-up (A); Schematic of experimental set-up (B)

\subsection{Control Unit}

Experimental set up works based on the principle of the linear actuator and its power supply is provided max. 5,5A.

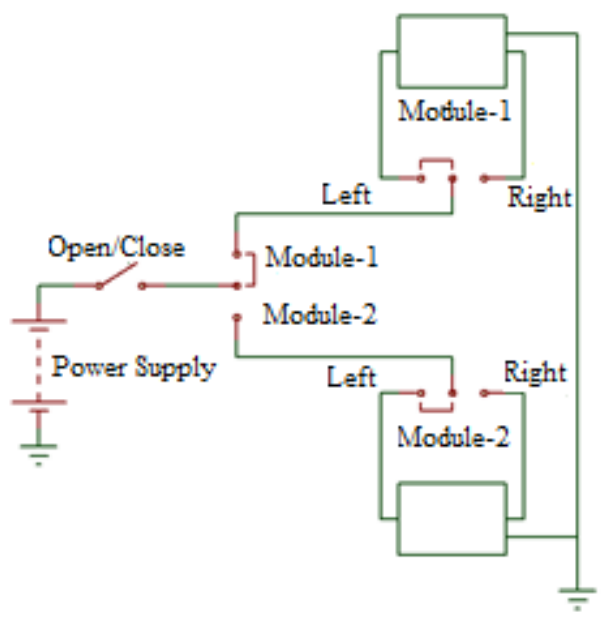

Figure 4. The control unit structure

(Figure.4) is shown control unit structure for experimental set-up. There is a switch named was Module-1 and Module-2. With this switch module is determined to be studied. Also running direction of the working module is also selected with the using key.

The cables used in the control unit is selected to be high current resistant.

\subsection{Modul-1}

The purpose of Module-1 set-up is to examine the parabolic movement in the horizontal plane of an object which is have $1.2 \mathrm{~kg}$ weight. This object is moved under favour of shape memory springs which are mounted on the right and left plane of the object.

To be able to move the object, 2.5 to $5.5 \mathrm{~A}$ current is respectively applied to both of the shape memory alloy springs which are the right and left plane.

Module-1 is designed to work of the SMA spring that it runs on the horizontal axis with the movable object weight of $1.2 \mathrm{~kg}$. This mechanism is used shape memory springs which are have same mechanical properties and same number of turn. Movable object is positioned at the exact plane. Shape memory springs were stretched by the deformation to maintain a position in which the object is located. A pen is added in front of the movable object.

The experimental setup is powered with the help of designed control panel. Module- 1 is activated from the control panel. The process is started by module- 1 way according to the direction of the desired position right or left-positioning. When the system runs in the right direction, the SMA spring at right side will 
return to its original position with the shape memory effect. The same issue applies to work in the left direction of the object. This time the system is operated in the left direction when the system runs in the left direction and SMA spring return its original position with the shape memory effect.

Parabolic actions are scratching in the millimetres paper and these actions are measured. To analyse the SMA spring behaviour, system is exposed to electric current respectively $5.5 \mathrm{~A}, 5 \mathrm{~A}, 4.5 \mathrm{~A}, 4 \mathrm{~A}, 3.5 \mathrm{~A}, 3 \mathrm{~A}, 2.5 \mathrm{~A}$ at the right or left- position, during the $10 \mathrm{~s}, 15 \mathrm{~s}$ and $20 \mathrm{~s}$.

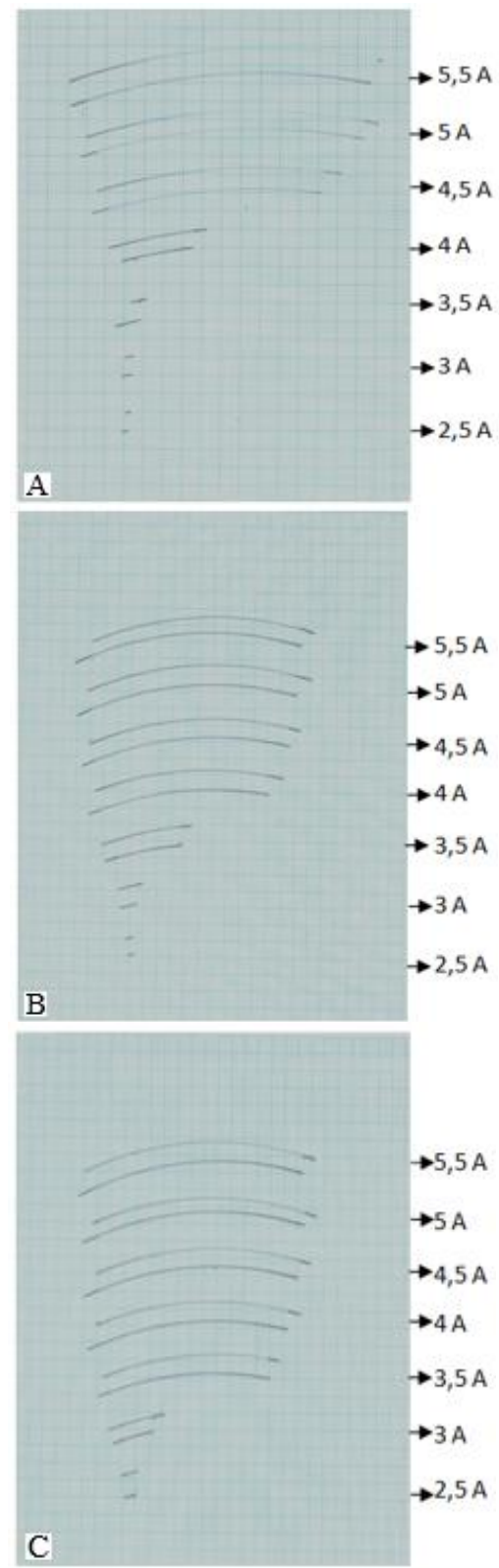

Figure 5. Distance parabolas: for 10s (A); for 15s (B); for 20s (C)

At the (Figure.7), scratching object movements are shown. These scratching are plotted during the $10 \mathrm{~s}, 15 \mathrm{~s}, 20 \mathrm{~s}$ and between $2.5 \mathrm{~A}-$ $5.5 \mathrm{~A}$ electric current in the range of $0.5 \mathrm{~A}$. Thus, depending on the different times and different electric current ranges, SMA spring behaviour are observed and mechanical behaviour data are recorded

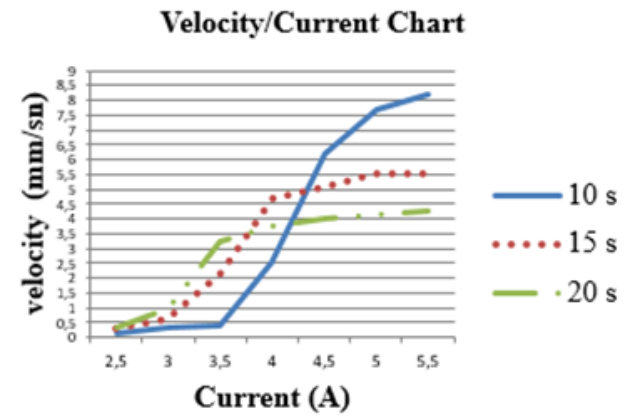

Figure 6. For 10s, 15s and 20s velocity-current diagram

(Figure.6) is shown the velocity gradient according to using electric current to SMA springs. It is shown that, applied current is increased, SMA spring velocity is increased. Obtaining velocity in the specified time range is examined, 10s-term movement application of the spring appears to have the highest acceleration and speed.

\subsection{Module-2}

A cylinder mechanism is designed with SMA spring for Module2. The purpose of this cylinder mechanism is to examine obtaining velocity in consequence of time-depletion data. These data are obtained by two SMA springs, which are have same mechanical behaviour and different number of turn, 2.5A and 5.5A current range of working.

At this module, SMA springs have been used in different numbers with the same characteristics. One of the spring in the system is pulled and another one is pushed in the process. Because of the used cylinder length is fixed equal number springs are limited the movement of the piston. Therefore, using different number of turn is increased measurement distance and provided maximum extension.

Module- 2 is activated from the control panel. The process is started by Module-2 according to the direction of the desired position forward or back-positioning. For forward movement, switch is selected "right" position and it moves advanced end position.

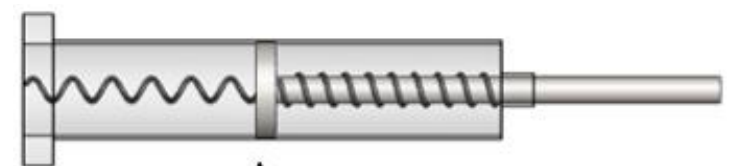

A

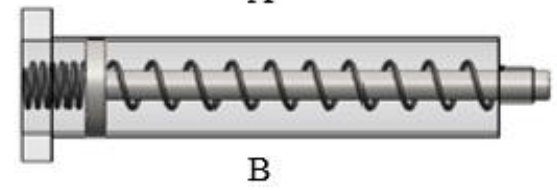

Figure 6. Module-2 Cylinder Positions: Advanced end-position of the cylinder (A); Back end position of the cylinder (B)

For back movement switch is selected left-position and cylinder moves its back end position. To analyse the SMA spring behaviour, system is exposed to electric current respectively $5.5 \mathrm{~A}, 5 \mathrm{~A}, 4.5 \mathrm{~A}, 4 \mathrm{~A}, 3.5 \mathrm{~A}, 3 \mathrm{~A}, 2.5 \mathrm{~A}$ at the right or left-position, during the $10 \mathrm{~s}, 15 \mathrm{~s}$ and $20 \mathrm{~s}$. 


\section{Forward-Back Motion Velocity/Current Chart}

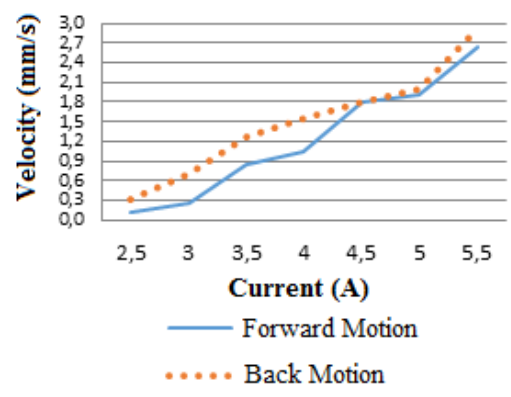

Figure 7. Module-2 Cylinder Positions

(Figure.7) is shown the velocity gradient according to using electric current to SMA springs. Speed differences at the forward and back movement are occurred for different number of turn of SMA springs.

\section{Conclusion}

In this study, an experimental set-up is developed to determine mechanical and working properties of the SMA that have great importance for industrial applications. By using experimental setup, SMA materials are tested which have different number of turn and have same mechanical properties. Set-up successfully measured shape memory springs' behaviour at the different electric current.

This study is shown, velocity of the SMA spring and applied electric current are proportional. With the increase of the applied current value, temperature of the springs is increased. On condition that, increasing temperature of the SMA springs, it is provided that, springs return their original shapes more quickly. Module-1 experiments are helpful to determine optimum working times. Module- 2 experiments are shown that in addition of the current value, number of spring turn is decisive for spring velocity

\section{References}

[1] Ming H. Wu and L. Mcd. Schetky. (2000), "Industrial Applications for Shape Memory Alloys", Proceedings of the International Conferance on Shape Memory and Superelastic Technologies, Pacific Grove, California, P.171-182

[2] Huang, W. (1998)," Shape Memory Alloys and Their Application to Actuators for Deployable Structures", University of Cambridge, Peterhouse

[3] G.W. Xu, D.C. Lagoudas, D. Hughes, and J.T. Wen (1997), "Journal of Intelligent Materials and Structures."

[4] Buehler, W. J. (17.07.2013). Re-Shaping-the-Future-withShape-Memory-Alloyshttp://www.biomedicine.org/biology-technology-1/Re-Shaping-the Futurewith-Shape-Memory-Alloys---SMA-Starter-Kit-10282-1/

[5] Yurtsever, Ö., (2013) http://ozguryurtsever.com/NiTiNol-2. (09.03.2014)

[6] Donmez B. et al, (2010), "Precise position control using shape memory alloy wires" Turkish Journal of Electrical Engineering \& Computer Sciences, Vol.18,No.5

[7] Toi Y, et al, "Finite element analysis of superelastic, large deformation behaviour of shape memory ally helical springs", Computer\&Structures, Vol:82, Issues:20-21 P.1685-1693 